\title{
EL RÉGIMEN SOCIAL DE LA FORESTAL EN SUS PRIMERAS DÉCADAS. CONDICIONES DE VIDA EN EL CHACO SANTAFESINO (1900-1920)
}

\author{
The social regime of La Forestal during its firsts decades. Living conditions in the \\ Chaco Santafesino (1900-1920).
}

Alejandro Jasinski

\begin{abstract}
Resumen
La historia social del Chaco santafesino en tiempos de La Forestal ha sido escasamente investigada. Más allá del clásico ensayo de Gastón Gori y algunos estudios específicos, los pocos relatos existentes han sido reiterativos y descuidaron aspectos importantes de la vida social de los poblados forestales. Este artículo, parte de una investigación más amplia, busca echar luz sobre algunos de estos aspectos. A partir de numerosos y variados testimonios poco o nunca explorados (informes oficiales, cartas de lectores, crónicas periodísticas, novelas y, principalmente, un folleto escrito por un delegado sindical en gira), buscamos representarnos muchas de las circunstancias que fueron configurando, durante las primeras dos décadas del siglo XX, un particular y asfixiante régimen social. No es de extrañar que las precarias características de la vivienda, la salud y la alimentación, la inexistencia de verdaderos servicios públicos, la complicidad de los agentes de justicia y seguridad y la falta de canales genuinos de participación cívica, animaran, hacia fines de la década de 1910, un inédito movimiento de protesta y un singular proceso de sindicalización.
\end{abstract}

$<$ La Forestal $><$ Chaco santafesino $><$ Régimen Social $><$ Sindicalización $>$

\begin{abstract}
The social history of the Chaco Santafesino in times of La Forestal has been poorly investigated. Beyond Gastón Gori's classic essay and some specific works, the scarce existing stories have been reiterative and they have ignored important aspects of the social life of the forest settlements. This article, which is part of a widest investigation, seeks to throw light on some of these aspects. Based on numerous and varied poorly explored testimonies (official reports, readers' letters, journalistic chronicles, novels and, principally, a leaflet written by an union delegate on tour), we seek to picture many of the circumstances that supported a particular and asphyxiating social regime during the first two decades of the 20th century. It is not surprising that the precariousness of housing, health and feeding conditions, the absence of adequate public services, the complicity of judicial and law enforcement officers and the lack of genuine channels of civic participation incited, by the end of the 1910s, an unprecedented protest movement and a singular process of unionization.
\end{abstract}

$<$ La Forestal $><$ Chaco santafesino $><$ Social Regime $><$ Unionization $>$ 
Jasinski. El régimen social de la forestal en sus primeras décadas.

\section{Introducción}

La historia social del Chaco santafesino en tiempos de La Forestal (1900-1960) ha sido parcial y escasamente investigada. Más allá del clásico ensayo de Gastón Gori (Gori, 1991) y algunos importantes estudios sobre problemas específicos, principalmente económicos-ecológicos-productivos (Bittloch y Sormani, 1997; Bünstorf, 1982; Ospital, 1990; Girbal Blacha, 1993), los pocos relatos existentes han sido reiterativos y descuidaron aspectos importantes de la vida social de los poblados forestales. Ni siquiera han llamado demasiado la atención los momentos más álgidos del conflicto social: el ciclo huelguístico de 1918-1921 y las huelgas de la década de 1930, por caso, apenas ocupan alguna línea en las varias historias del movimiento obrero argentino y afines (Abad De Santillán, 1971 y 2005; Iscaro, 1973; Belloni, 1960; Panettieri, 1959; Godio, 1989; Marotta, 1970; Palacios, 1960).

Este artículo, parte de una investigación más amplia sobre los orígenes del proceso de sindicalización en la región (Jasinski, 2012), busca echar luz sobre algunos de estos aspectos descuidados de la vida social. En la extensa y heterogénea literatura científica sobre las acciones colectivas y, dentro de ellas, sobre los movimientos sociales, una de las dimensiones del "mapa" analítico refiere al origen de los mismos (McAdam, Tilly, Tarrow, 1996). En este caso, al investigar la historia del ciclo huelguístico que tuvo lugar en las fábricas y montes de esta región entre 1918 y 1921, debimos remontarnos unas décadas atrás para observar los procesos productivos y las condiciones sociales de aquellos trabajadores y pobladores, a fin de comprender las características del escenario social que se configuró en la región durante las primeras décadas del siglo XX y que alimentan la explicación de aquel levantamiento popular que fue, al final, trágicamente sofocado.

Los capitales ingleses de la reputada La Forestal llegaron en 1906. Con ellos no comenzó la historia de la explotación de los bosques de quebracho, ni siquiera la extracción fabril del tanino. Pero cuando se hicieron presentes, recién ahí, comenzó a constituirse lo que elegimos denominar el verdadero régimen social de La Forestal, en el sentido de haber dado lugar a un conjunto de criterios explícitos y no explícitos que le permitieron a esta compañía de tierras, maderas y ferrocarriles, ser rectora y dominante en la vida social, económica, cultural y política de aquella región. El concepto de régimen social surge de la propuesta realizada por Cornelius Castoriadis, para referirse a la dominación presente en una organización social que no puede ser reducida a aspectos puramente económicos o técnicos-productivos (Castoriadis, 1988). Es decir, que no niega sino que excede al concepto clásico de "modo de producción", haciendo también alusión al modo de organización social, política y al modo de control de imaginarios y subjetividades. Si bien Castoriadis utilizaba este concepto en forma mucho más general ("capitalismo burocrático total" o "capitalismo burocrático fragmentado"), las características cerradas del dominio ejercido por la compañía británica en un espacio y tiempo delimitado nos permiten utilizar dicha noción. En este artículo, intentaré dar cuenta de algunos aspectos de la vida social en las primeras dos décadas de este régimen social, desde sus orígenes hasta el momento previo a su consolidación, que sucedió tras la masacre obrera de 1921. 
Las fuentes que utilizaremos son de diferente tipo y, en su mayoría, no exploradas. En primer lugar, nos serviremos de las ya conocidas descripciones contenidas en el clásico informe de Juan Bialét-Massé, escrito en 1904, requerido por el gobierno de Julio Argentino Roca (Bialét-Massé, 1985). En segundo lugar, usaremos crónicas periodísticas y cartas de lectores, la mayoría de ellas publicadas en el diario provincial Santa Fe. Asimismo, utilizaremos algunos pasajes de la novela de Roberto Vagni, Tierra extraña, escrita hacia 1949 y situada en el poblado de Villa Guillermina y sus alrededores (Vagni, 1949). Pero el elemento más interesante surge de lo escrito por un dirigente sindical hacia 1920. Se trata de Luis Lotito, un hombre del sindicalismo revolucionario, delegado de la FORA IX, quien visitó los poblados de La Forestal y plasmó todo cuanto vio en extensos informes, llenos de análisis, anécdotas y detalladas descripciones de los paisajes sociales y de la organización sindical en aquella región, que fueron publicados por el periódico de la federación novenaria, La organización obrera, y compilados entonces en un folleto de ochenta páginas, bajo el título de "Los trabajadores del Chaco, Formosa y Misiones".

Introduciré, en primer lugar, los aspectos que hicieron al predominio económico de La Forestal en la región. Luego, me referiré a las características que fue tomando el régimen social en aquellos poblados forestales. Finalmente, realizaré una apretada síntesis del inédito movimiento de protesta y singular proceso de sindicalización que tuvo lugar entre 1918 y 1921, en gran parte consecuencia de dicho régimen, y cerraré con algunas conclusiones y observaciones para trabajos futuros.

\section{La Forestal en el chaco santafesino}

El quebracho colorado es un árbol propio de las tierras sudamericanas, aprovechable por su madera y por su contenido tánico, subproducto éste muy utilizado para el curtido y teñido de las pieles de animales, cuyo resultado final se alcanza con la producción de zapatos, valijas, carteras y muchos otros bienes de la industria del cuero. Específicamente, este árbol se encontraba en forma abundante en los bosques y selvas de la región chaqueña argentina, que contiene a las actuales provincias de Formosa, Chaco, prácticamente todo Santiago del Estero, el oriente salteño y el norte de Santa Fe. En esta última provincia, la llamada cuña boscosa abarcaba los departamentos del norte y noreste santafesino: General Obligado y Vera.

La explotación forestal sistemática comenzó hacia mediados del siglo XIX. En primer lugar, la madera del quebracho era utilizada para la construcción de muebles y edificios, durmientes ferroviarios, embarcaciones, puentes, postes de telégrafo y alambrado de campos. También, como fuente de energía para locomotoras y fábricas. Pero pronto se descubrieron sus propiedades tánicas, dando inicio a la fase moderna de la industria del quebracho en el país: los capitales alemanes, franceses e ingleses, que hasta entonces se llevaban los rollizos del quebracho para Europa, donde se encontraban las principales fábricas de tanino del mundo, decidieron cambiar la ecuación y arribaron con sus establecimientos e ingenieros a esta región. Aquí, en algunos pocos lugares, se extraía el tanino de forma primitiva, pero la llegada de las primeras fábricas de tanino produjo 
Jasinski. El régimen social de la forestal en sus primeras décadas.

un cambio fenomenal, abortando los intentos de transformar al norte de Santa Fe en una zona de colonias.

La primera fábrica de tanino se construyó en Corrientes, en la localidad de Peguajó, en 1880. Recién 15 años más tarde se instaló una nueva fábrica, esta vez en Santa Fe, en la localidad de Fives Lille (hoy Vera y Pintado). En 1898, se construyó una fábrica en Calchaquí, también en la provincia santafesina. Hacia 1902, de la fusión de estas dos últimas fábricas, de capitales franceses y alemanes, nació la Compañía Forestal del Chaco, la primera conocida como La Forestal. En pocos años, esta empresa adquirió 500 mil hectáreas de bosque en propiedad y 400 mil como arriendo y concesión; instaló fábricas de tanino en Villa Guillermina (1903) y en La Gallareta (1906); construyó 170 kilómetros de ferrocarril particulares y un puerto propio en Piracuá; y se hizo además con la aserrinera de Florencia. En 1904, se construyó la fábrica de Tartagal, esta vez con capitales estadounidenses.

Recién en 1906 se fundó la Forestal Land, Timber and Railways Company Ltd., con sede en Londres. Su registro en Buenos Aires la renombró como Compañía de Tierras, Maderas y Ferrocarriles La Forestal Ltda. Al momento de su fundación, esta empresa de capitales británicos compró la Compañía Forestal del Chaco, haciéndose con todas sus propiedades, y en poco tiempo se convirtió en la dominante absoluta del mercado del quebracho. Ahora sí, nacía la verdadera La Forestal. Los datos que aportaremos ahora dan cuenta de su avasallante expansión.

En 1907, compró la fábrica de Peguajó. Un año más tarde, una instalada en El Mocoví. En 1909, estableció un contrato de compra de la producción de la fábrica de Quebrachales Fusionados en Puerto Tirol, compró la Compañía Argentina de Lanchas y cerró la fábrica de Peguajó. En este momento pasó a tener una posición casi monopólica en la oferta exterior de rollizos y tanino. En 1910, compró el ferrocarril Villa Ana-Colonia y Ocampo-Puerto Ocampo. En 1911, cerró la fábrica de El Mocoví, pero fundó la de Villa Ana. En 1913, en una operación sancionada dos años más tarde por defraudación al fisco provincial, se fusionó con la Compañía de Tierras de Santa Fe, sumando 805 mil hectáreas de bosque como propiedad, tres estancias de 220 mil hectáreas y 96 kilómetros de ferrocarril particular; y se hizo con la Argentine Quebracho Company, con sus 280 mil hectáreas de bosque y la fábrica de Tartagal. Por entonces, se hablaba ya del "pulpo" de La Forestal ${ }^{1}$.

En 1914, cerraba la fábrica de Calchaquí, generando nuevamente una opinión crítica en los medios provinciales, desde donde se exigía al gobierno provincial convertir a esta localidad, con tierras de primer orden aptas para producir lino, trigo, maíz y maní, "en la más linda de las colonias del norte”2. Más tarde, en 1920, la compañía británica adquiría la fábrica de Fontana, en Resistencia, cuando se presentaba una crisis de la exportación del tanino. Su actividad quebrachera no impidió que, además, dispusiera de numerosas estancias agrícolas y ganaderas. Como vemos, tan pronto como llegó, desplegó

\footnotetext{
${ }^{1}$ Diario Santa Fe, 27/1/1914.

${ }^{2}$ Diario Santa Fe, 3/10/1914, 10/6/1915 y 11/6/1915.
} 
una impresionante ingeniería empresarial, hizo y deshizo a gusto. Hacia 1920, concentraba el $80 \%$ de la oferta de tanino ${ }^{3}$.

El destino de la industria quebrachera estuvo estrechamente vinculado al desarrollo ferroviario en la región. Las primeras fábricas de tanino se instalaban cerca de los bosques. Esto permitía que el transporte de rollizos se pudiera hacer por carros o mediante cortos trayectos ferroviarios. Sin embargo, al avanzar la frontera de explotación, se precisaron líneas férreas de mayor longitud. Por ello mismo, las compañías forestales se hicieron, en 1902, del Ferrocarril de la Provincia de Santa Fe, pero además construyeron centenares de kilómetros de vías privadas. Sólo La Forestal llegó a tener una extensión aproximada a los 400 kilómetros. El mismo empuje productivo repercutió también en el crecimiento de la actividad naviera por los ríos de la región.

\section{El régimen social de La Forestal}

Quienes prestaron sus brazos a la actividad forestal en el norte de la provincia de Santa Fe eran, en su gran mayoría, migrantes correntinos. También los había provenientes de otras provincias e incluso del Paraguay. Éstos en gran medida se dedicaban a las tareas menos calificadas, ya fueran obrajeros del monte (hacheros, labradores, leñadores, carreros, guincheros) u obreros de fábrica (aserrinero, tonelero, fundidor, peón y numerosos oficios más). Había también un número pequeño de personas dedicadas a otras tareas diferenciadas: empleados de servicios y administrativos, ingenieros y gerentes, éstos últimos en su mayoría extranjeros, principalmente ingleses (Bialét-Massé, 1985; Ramírez y Quarin, 2005; Iñigo Carrera, 1988).

En otra oportunidad he descrito las características de estos trabajadores y de las tareas que realizaban, tanto en el obraje como en las fábricas y las formas en que era remunerado su trabajo (Jasinski, 2012). Pero en este artículo -como adelantábamosnos proponemos dar cuenta de las condiciones de vida de estos trabajadores de obrajes y fábricas de tanino en las primeras décadas del siglo XX. Todos ellos vivieron en un particular espacio social que se fue conformando bajo el omnipresente dominio y control ejercido por La Forestal. En lo que sigue, haremos descripciones pertinentes a diferentes dimensiones que tomó dicho régimen: la característica física de los poblados forestales, los aspectos de salubridad y sanitarios, el sistema de vales y provisiones y otros referentes al transporte, la educación, la seguridad, la justicia y demás servicios públicos, para finalizar con algunas notas sobre las características de la vida política en estos poblados.

\section{Los poblados forestales}

Poblados forestales eran todos aquellos lugares donde habitaba un número más o menos importante de personas, desde los lugares más provisorios, tipo campamentos como las "arranchadas" o "ramadas", hasta los más importantes, como los centros de

\footnotetext{
${ }^{3}$ Respecto de los números de producción y exportación de rollizos y tanino, ver el trabajo de mi autoría, previamente citado.
} 
Jasinski. El régimen social de la forestal en sus primeras décadas.

obrajes y los pueblos tanineros. La primera referencia proviene del informe de BialétMassé. Al visitar los obrajes, en 1904, además de describir las características del trabajo y oficios, también se refirió a los aspectos más amplios de la vida en aquella región. En primer lugar, figuró de forma general las características del paisaje social de los obrajes, de los cuales sostenía que, desde Calchaquí hasta la sabana norte, ninguno presentaba variaciones sensibles. Se trataba de "la misma ranchería de palo a pique con barro, desordenada, desigual, con grandes claros, reunida aquí en grupo, dispersa más allá" (Bialét-Massé, 1985). Algunas administraciones de obraje -decía- podían tener alguna construcción menos precaria, como una casa regular de dos aguas, con una o dos piezas para el administrador en el fondo, pero lo demás estaba "sin orden ni concierto" (BialétMassé, 1985).

El obraje tenía su centro en la playa para rollizos, desde el cual disparaban varias picadas que se internaban en el monte. Alrededor de esta playa central, podían existir -como establecía nuestro primer informante- un rancho más o menos precario para el contratista o algún mayordomo. Pero los hubo luego que también tenían viviendas obreras y alguna que otra institución social, como la escuela o un club recreativo o mutualista. Desde este núcleo poblacional, el camino se dirigía -algunos kilómetros más allá- hacia una playa ferroviaria, donde se cargaban los rollizos a las chatas del tren, con destino a las fábricas o puertos. Esta estación del ferrocarril o paraje podía también ser un poblado más o menos pequeño, con existencia de algún almacén, un aserradero y un boliche.

Al internarse en las picadas que salían desde el centro del obraje, Bialét-Massé alcanzó varias "arranchadas", donde vivían y trabajaban los hacheros. Se trataba de un campamento de trabajo, de mediano tamaño, que el informante no alcanza a diferenciar con exactitud de la "ramada”, la cual, al parecer, se encontraba más adentro en el bosque, llegando por nuevas picadas, y que consistía en el nada lujoso tendido de unos pocos palos y algunas hojas, sin necesidad de cobertura de paja y barro:

Algunos tienen una carpa que les cuesta cinco o seis pesos: eso es el lujo. Los más clavan cuatro estacas en el suelo, y a un metro de altura hacen una cama de palos clavados sobre tres largueros y algunos sobre dos; ponen encima bolsas llenas de pasto seco: ese es el colchón; en la cabecera ponen astillas de quebracho por almohada. De la sábana no hay idea; sobre cuatro palos montan el mosquitero, que es de zaraza rala; y allí duermen sin más techo. Cuando llueve, en vez de dormir sobre la cama, duermen debajo: ese es su abrigo. Si se les pregunta por qué no hacen una ramada cubierta de paja y barro, contestan invariablemente: ¿y para qué? Así estamos bien. Tenemos que cambiar a cada instante de lugar; sería mucho trabajo perdido (Bialét-Massé, 1985).

En contraste con este paisaje rural, encontramos a los pueblos de fábrica. Ninguno, hasta la llegada de La Forestal, se había desarrollado bastante (Villa Guillermina, Villa 
Ana, Tartagal o La Gallareta). En otros casos, directamente ni existían (Santa Felicia). Su fisonomía era bastante similar. Alrededor del establecimiento fabril se encontraba los edificios administrativos, el almacén de ramos generales, la panadería y la carnicería. Eran edificios grandes, que podían tener más de cincuenta metros de frente. Cerca del establecimiento industrial, se construían las casas del gerente y del ingeniero, sin duda alguna, las personas con mayor poder en el pueblo. También se encontraban las casas de otros empleados jerárquicos y la casa de visitas, un lujoso chalet donde se hospedaban los viajeros con dinero o cierta distinción social. Más allá, se ubicaba la plaza central, alrededor de la cual se construía la comisaría y el juzgado de paz, un hospedaje y la escuela. Contaban estos pueblos también con clubes sociales, diferenciados para obreros y para empleados. Y finalmente, distribuidos a lo lejos, se ubicaban las viviendas obreras, en este período, ranchos construidos con materiales muy precarios. Estaban también las llamadas solterías, diferenciadas para empleados y obreros de fábrica. Todavía hoy, una fugaz visita a algunos de estos pueblos permite percibir esta distribución espacial.

Si Bialét-Massé no se refirió a ellos en su oportunidad, en vistas de su reciente creación, quien sí lo hizo de forma minuciosa fue, quince años más tarde, Luis Lotito, cuyo viaje al norte fue parte de las giras realizadas por todo el país por los delegados de la FORA IX. Este dirigente sindical fue encomendado en un viaje que le llevó más de siete meses. Su gira comenzó en enero de 1920 y ya en marzo estaba pisando, por primera vez, las tierras de La Forestal. Sus “Impresiones e informes del delegado”, publicadas semanalmente en La Organización Obrera y luego compiladas en un folleto de ochenta páginas con el título "Los trabajadores del Chaco, Formosa y Misiones", nos prestan análisis, anécdotas y detalladas descripciones de los paisajes sociales y de la organización sindical en aquella región, con el particular interés de que se realizaba en el mismo momento en que tenían lugar las huelgas de 1918-1921.

El 25 de marzo de 1920 Lotito llegó a Vera y pronto se embarcó hacia Santa Felicia, donde -según dijo- dio su primer paso en el "gran ducado" de La Forestal. Su viaje se completó con las visitas a La Gallareta, Las Chuñas, Los Claros, Colmena, Arroyo del Rey, Tartagal, Villa Ana y Villa Guillermina. En referencia a las características físicas de los poblados, de todo lo que vio, lo que más preocupó a Lotito fue el problema de la vivienda. Sólo nos detendremos en algunas de sus muy extensas descripciones.

Uno de los poblados que visitó fueron los de Las Chuñas y Los Claros, pertenecientes a la compañía obrajera Las Selvas del Chaco, vinculada a La Forestal. Lo primero que observó fueron los ranchos de barro y paja, "semejantes a los descriptos por nuestra literatura campestre"4. Al delegado sindicalista le alarmaba el carácter provisorio de las viviendas, de las cuales decía: "No tienen los arreglos necesarios, porque hay la creencia de que todo es provisorio; sin embargo, pasan años y años y lo provisorio se hace definitivo, viviendo siempre en la estrechez, sin comodidades" ${ }^{\prime 5}$.

Hay que destacar que la escasez de la vivienda y, por ende, el hacinamiento, era un rasgo muy común en aquella zona, incluso en pueblos como el de Villa Ana, donde

\footnotetext{
${ }^{4}$ Periódico La organización obrera, 10/4/1920.

${ }^{5}$ Ibíd.
} 
Jasinski. El régimen social de la forestal en sus primeras décadas.

por presión de las huelgas obreras se estaban mejorando las construcciones. Pero en su mayoría, éstas eran de pésima calidad, tal como lo observaba en el pueblo de La Gallareta:

Las habitaciones construidas para albergar a los obreros de la fábrica de tanino son bastante malas y su aspecto desagradable. (...) Su construcción es de empalizadas de troncos revestidas de barro y paja. Techo de zinc o paja, muy bajo, siendo causa de toda clase de molestias. En verano, las chapas de zinc se calientan, convirtiendo la habitación en un horno (...) Los muros, llenos de grietas, no abrigan contra el frío, ni el viento. Son covachas insanas, sin piso ni aberturas para la luz. ${ }^{6}$

Al llegar a Tartagal, con una población de 1.500 habitantes, la situación empeoraba notablemente, pues el aspecto de las habitaciones era "peor" que en los otros sitios visitados. Había menos casas de material y más ranchos en mal estado, cuyos pisos de tierra y al mismo nivel que los del exterior, se convertían en pantano en días de lluvia. Asimismo, las casas tenían pocas ventanas y las pocas existentes estaban tapeadas, por lo que no ingresaba la luz natural. Tampoco tenían los hogares los elementos necesarios para el mantenimiento, comodidad y cocina. Era tal la situación que -según comentaba"deprimía moralmente a sus moradores y afectaba su salud"”. Tal era la situación que el poblado más grande, el de Villa Guillermina, era descrito como "una ranchería uniforme, ajena a todo buen gusto y confort propios de la habitación humana"'.

Como vemos, casi dos décadas más tarde, Lotito confirmaba la precariedad de las características de los poblados descritas por Bialét-Massé a comienzos de siglo. Una de las consecuencias obvias de ello no podía ser sino la presencia de numerosas enfermedades, producto del propio trabajo forestal, pero también de las duras condiciones de la vida que se llevaba.

\section{Las "enfermedades del quebracho"}

Como decíamos, bajo aquellas condiciones, cuesta muy poco imaginar que no tardaran en aparecer las enfermedades, particularmente en las estaciones en las que irrumpían los ejércitos de la fauna. En efecto, la vida en el monte podía soportarse malamente en invierno, estación fría que, según Bialét-Massé, se llegaba a confundir con "el paraíso". Pero la situación variaba notablemente al acercarse los azotes veraniegos:

...el campo comienza a cubrirse de aguas, a enfangar los caminos, y aparece el mosquito, que con el polvorín (especie de mosquilla brava, mordedora, irritante e insoportable), constituyen el martirio del obrero, martirio que se va agrandando hasta el mes de diciembre, en que se hace tan

\footnotetext{
${ }^{6}$ Ibíd.

${ }^{7}$ Periódico La organización obrera, 17/4/1920.

${ }^{8}$ Periódico La organización obrera, 8/5/1920.
} 
irresistible que muchos se van a las cosechas o se vuelven a sus pagos, huyendo de la sabandija, como ellos llaman a estas plagas; no hablo del pique, y de las víboras, leones y alguno que otro tigre y las colmenas, porque a esto no se les hace caso (Bialét-Massé, 1985).

Llamativamente, el informante observaba que a las víboras, leones o colmenas, "no se les hace caso". Sin embargo, el diputado Belisario Salvadores denunció años más tarde que, en Golondrina, por caso, los accidentes con picaduras de víbora eran tan frecuentes que los tribunales debieron reconocerlos como accidente de trabajo (Gori, 1991). Pero no eran los únicos padecimientos que sufrían los pobladores de aquella región. Nuestro cronista hablaba también de la denominada "enfermedad del quebracho", una serie de infecciones propias del trabajador que se enfrentaba por primera vez a las esquirlas del árbol en tala. Los afectados por dicha enfermedad sufrían de cansancio del cuerpo, pesadez en la cintura, dolor de cabeza frontal, fiebre y edemas en las piernas, pies y a veces de los antebrazos. Esto impedía que se moviera por un tiempo, que a veces podía llegar a un mes y más, cuando no eran afectados por secuelas perdurables que los dejaba afuera de toda actividad productiva de por vida (Bialét-Massé, 1985).

Pero también existían enfermedades ya conocidas. Del paludismo -contaba-, un poco; de la viruela, que cuando se presentaba hacía estragos; y del tifus, que prendía con facilidad, por la suciedad y putrefacción de las basuras y por los pozos que se usaban como letrinas, "algo realmente inmundo", opinaba. Si esto decía el primero de nuestros informantes, más revelador es el recuerdo de un habitante de la zona y protagonista del movimiento sindical en los años '30. José Bernabé Vargas, quien trabajó como peón de campo, guinchero y aserrador para La Forestal, recuerda el "azote de la epidemia de viruela negra" en Villa Guillermina, en los años 1910/1911, llegada luego del ataque del sarampión (Bernabé Vargas, 2003).

También Lotito, en 1920, notaba la carencia de servicios básicos y de la higiene indispensable. De Tartagal, por ejemplo, decía que se presentaba un "espectáculo repugnante":

En gran parte del pueblo no hay w.c. Esto representa una incomodidad muy grande $\mathrm{y}$ es causa de suciedades $\mathrm{y}$ espectáculos repugnantes. El agua no es abundante (...) Sin embargo, no es un imposible establecer cañerías porque así como se han puesto canillas en algunas esquinas, con un gasto poco mayor se habría puesto en cada casa. ${ }^{9}$

En Villa Guillermina, el panorama no era muy diferente, con escasos baños ubicados en el centro de la manzana:

Faltan los w.c. necesarios y algunos que hay, mejor no

\footnotetext{
${ }_{9}^{9}$ Periódico La organización obrera, 17/4/1920.
} 
Jasinski. El régimen social de la forestal en sus primeras décadas.

recordarlos, porque en vez de ser un servicio de higiene son un foco de infección (...) aparte de ser un sitio de pestilencia, en donde prosperan una variedad de insectos y gusanos a cual más inmundos. He viso algunos de estos semilleros de microbios construidos con chapas de cinc, las cuales en sus partes inferiores están podridas y dejan grandes aberturas que no resguardan ni siquiera de la mirada. ${ }^{10}$

A la existencia de estos "focos de infección" se sumaba la carencia de agua, la cual, en la mayoría de los lugares, debía buscarse en baldes a cientos de metros de distancia. En Los Claros, cuando no se podía traer el agua en baldes -decía el viajerose intentaba aprovechar el agua de lluvia, aún cuando luego de unos días conservada, perdía su bondad: "Su descomposición por efecto de la alta temperatura, la desnaturaliza y puebla de microbios". ${ }^{11}$

Claro, todo ello se completaba con la inexistencia de acciones de prevención y, aún más, con la falta de un sistema hospitalario acorde a las enfermedades que aquejaban a aquellos habitantes. Esta precariedad era denunciada ya en 1915 por el vecino de La Gallareta Juan Gervazoni:

En estos feudos no se admite el asiento o establecimiento de médico nacional. Por eso en pleno pueblo de La Gallareta se presenció el triste espectáculo del fallecimiento de una pobre mujer que al dar a luz murió por falta de asistencia médica bajo el cruel desamparo y la sombra piadosa de un algarrobo. ${ }^{12}$

En los comienzos de La Forestal, contaban los pueblos con alguna sala de sanidad, pero sólo Villa Guillermina, el pueblo más grande y sede central de la empresa en la región, contaba con un hospital. Los salarios de los trabajadores llegaban con descuentos por atención médica y provisión de medicinas. Cuando Lotito visitó Villa Guillermina, anotaba, con cierta ironía:

Hay aquí -¡Oh filantropía!- un hospital. Lo he visto. Sin ser lujoso, su construcción responde a tal fin, no ocurre así con la provisión de medicamentos. No se recetan específicos ni existen en la farmacia anexa los necesarios. El servicio del hospital no es gratuito. La compañía descuenta el $2 \%$ de los jornales para socorro en caso de enfermedad. Pero el socorro es deficiente. La caja, como es lógico suponer, no la administran los obreros que pagan, sino la compañía que cobra, sin tener aquellos ningún contralor ni representación. ${ }^{13}$

\footnotetext{
${ }^{10}$ Periódico La organización obrera, 8/5/1920.

${ }^{11}$ Periódico La organización obrera, 10/4/1920.

${ }^{12}$ Diario Santa Fe, 10/6/1915.

${ }^{13}$ Periódico La organización obrera, 8/5/1920.
} 
Pero a la falta de estructura hospitalaria se sumaba el problema de la discriminación en la atención médica. Hacia 1919, los trabajadores de Villa Ana se quejaron por nota a la superioridad por el desempeño del médico del pueblo, doctor Mautone, de quien solicitaban su destitución, "en virtud de que este facultativo no atiende en debida forma a

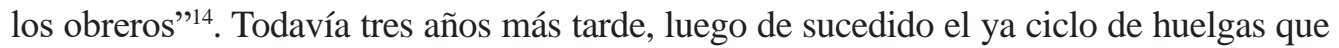
describiremos más adelante, la situación no fue muy diferente. A raíz de un serio malestar, una pobre señora de Margarita debía ser trasladada hasta el consultorio médico que la compañía inglesa tenía en La Gallareta, a unos quince kilómetros. Para ello, se solicitó a la gerencia autorización para utilizar el tren de la empresa, pagando el correspondiente pasaje. Sin embargo, la respuesta fue negativa. La mujer fue llevada a pie por sus parientes, pero al llegar su enfermedad se había agravado y a los dos días falleción ${ }^{15}$.

\section{La estafa de los almacenes y vales}

Además del martirio de la vivienda y la salud, los trabajadores debían sufrir una pésima alimentación, producto del perverso sistema de proveedurías y vales implementado.

Uno de los principales eslabones de este sistema lo constituían los almacenes, a los que acudían cada semana los trabajadores para hacerse del alimento. Como los dueños del obraje o fábrica eran los únicos que vendían provisiones en aquellas zonas, se permitían cometer ciertas arbitrariedades, utilizando para ello los bien conocidos descuentos por adelanto, la suba de precios, la sujeción por deudas y hasta la moneda propia.

En este último caso, la empresa taninera, el dueño de un obraje o el contratista en el monte, extendían vales particulares que llevaban el sello de la compañía, que sólo servían para ser utilizados en sus almacenes y a precios inflados. De lo contrario, se negociaban con descuento para convertirlos en peso moneda nacional. Una ficha o vale podía, por ejemplo, llevar la inscripción "Un kilo de carne". Su extendido uso mereció críticas que llegaron a los recintos legislativos provinciales y nacionales, logrando recién en 1925 la sanción de una ley nacional prohibitiva de este medio de pago, haciendo obligatorio el uso de moneda nacional de curso legal (Brianza, 2007).

Este perverso sistema se había instalado tempranamente y fue bien descrito por Bialét-Massé, al describir la situación creada por algunas compañías:

...las hay que llevan la explotación a extremos increíbles; tienen lo que se llama aviador, que los sábados adelanta plata a los obreros, pero la plata consiste en unas ruedas de lata que se suponen que valen un peso; el que gana va a la proveeduría a convertirlas; pero le dicen que las latas no son dinero y que no se convierten sino en mercaderías, y ahí de los precios: 200 a 400 por ciento es lo menos que se carga (Bialét-Massé, 1985).

Ello no era todo. Además del descuento y la obligación de comprar con ese

\footnotetext{
${ }^{14}$ Diario Santa Fe, 13/9/1919.

${ }^{15}$ Diario Santa Fe, 24/4/1922.
} 
Jasinski. El régimen social de la forestal en sus primeras décadas.

"dinero" mercaderías a precios inflados, los trabajadores debían sufrir el robo directo en la entrega de los alimentos:

La proveeduría es rabiosamente explotadora, y en muchas partes estafa. Los precios de las proveedurías menos explotadoras son: la carne, que se vende en Vera a dieciocho centavos, se les da de veinte a veinticinco; no es esto nada; se les roba en el peso, en proporciones escandalosas; en vez de diez kilos se les da siete (...) y como si esto no fuera bastante se llevan a las carnicerías carne de animales muertos de enfermedad, cansados y lastimados (Bialét-Massé, 1985).

Igual que con la carne, sucedía con la galleta, el maíz, la yerba y la bebida. Pero donde la explotación era "más atroz" era en la ropa. De esta forma, los escasos pesos que vimos que el trabajador ganaba por sus tareas, se los robaban en el negocio de las provisiones. En la novela Tierra extraña, se describía lo que se llamaba el "punto neurálgico de la explotación del hombre por el hombre":

La trágica trilogía de la 'administración' que reemplaza al almacén, la casa de bailes públicos y la comisaría administrando las canchas de taba, era lo que absorbía cuanto ganaba el hachero del monte. La 'administración' adquiría, por ejemplo, el fideo a veinte centavos y lo vendía a setenta. El kilo de yerba a setenta centavos y lo vendía a un peso y ochenta. Y en esa proporción toda la mercadería (Vagni, 1949).

Por supuesto, este sistema de estafas no estaba exento de competencia, prohibida pero legítima. Los llamados "turcos" y "judíos" amenazaban al monopolio y, por ello, podían ser perseguidos de forma implacable, cuando no se integraban al esquema propuesto (Gori, 1991).

La estafa del sistema de proveedurías y vales, se completaba con el mecanismo de la sujeción por deuda, garantizado por la más estricta violencia policial. Escribía BialétMassé:

"El jefe político de Vera me ha referido que en algunos obrajes, para explotar a los obreros, les fían largo y luego pretenden que la policía evite que se vayan, llegando hasta pedir que se los tengan de noche en la barra y los suelten de mañana para trabajar" (Bialét-Massé, 1985).

Todo lo descrito hasta aquí hacía al abaratamiento de la mano de obra y, por supuesto, al abultamiento de las ganancias empresarias. Ello no pasaba desapercibido para el informante oficial en 1904 y tampoco para los funcionarios del Departamento Nacional del Trabajo, una década más tarde. La Memoria del DNT correspondiente a 1912 resumía los datos expuestos calificando de "extremadamente precaria" la situación 
de estos trabajadores. Tres años más tarde, el inspector José Elías Niklinson establecía que los datos que se obtenían en las conversaciones con los obreros rara vez coincidía con el cálculo de las planillas de jornales o de las propias libretas de los peones, resultando los jornales aún más bajos en estos casos (Gori, 1991).

Estos esquemas, como vemos, existían antes de que aparecieran los capitales británicos de La Forestal. Pero cuando avanzó la explotación del bosque y en la región apareció este gran pulpo, la situación empeoró notablemente para los trabajadores del monte, pues sufrían un doble robo, al ser la empresa -en muchas ocasiones- la que proveía los alimentos y herramientas de trabajo a los mismos dueños de obraje o contratistas, antes de que llegaran al obrajero.

Hacia 1920, Lotito también se refirió al sistema de proveedurías: la falta de higiene, la mala calidad de las mercaderías, la pésima atención y el problema de los pagos, junto al abuso policial, constituían todavía el escenario alimenticio. En Tartagal, por ejemplo, Lotito observaba que el servicio de abastecimiento es "otra de las penurias de este pueblo". Explicaba que ello sucedía porque un solo empleado de almacén era destinado a atender a más de cuatrocientas familias. "La gente llenaba el despacho desde que se abría hasta la hora de cerrarse, en grupos de centenares", escribía Lotito, para luego agregar: "La espera era frecuentemente de horas y horas..." ". Sucedía así que un tercio de las personas se quedaban sin carne: “...después de una espera de largas horas, se concluye la carne y los más se vuelven como han ido. (...) Así se van a trabajar después de masticar un poco de pan y mucha rabia"17. Tal situación, como dice, no podía suceder sin empujones, apretones y, por supuesto, sin conflictos. Por ello, la empresa destinaba guardias privados para seguridad. De Tartagal, Lotito contaba que la policía se hacía presente en el despacho y “el agente, con un látigo en la mano, se paseaba para imponer paciencia al que no la tuviese"18.

En otros lugares, como Arroyo del Rey, además de los altos precios, aparecía el muy mal estado de los alimentos y el robo con la balanza:

Aquí no hay panadería ni carnicería. El pan y la carne hay que solicitarlos a Tartagal. Esta última, cuando llega, está descompuesta, pues la remiten después de un día de haber sido sacrificado el animal. Y como no hay otra cosa, se le acepta así, aunque sea nociva para la salud. El peso que se manda está lejos de ser el justo. En calidad y en cantidad se explota enormemente. ${ }^{19}$

El problema, como vemos, no era sólo la desidia de la compañía en la atención alimentaria, sino el monopolio. Sólo en Villa Guillermina, encontramos algunos “boliches" particulares, establecidos en ranchos estrechos y bajos, donde las mercaderías estaban

\footnotetext{
${ }^{16}$ Periódico La organización obrera, 17/4/1920.

17 Ibíd.

18 Ibíd.

${ }^{19}$ Ibíd.
} 
Jasinski. El régimen social de la forestal en sus primeras décadas.

bastante descuidadas. Pero éstos -se decía- eran escasos para responder a las necesidades del consumo.

\section{Los servicios en la "república independiente"}

A las situaciones descritas se sumaban una serie de inconvenientes para los pobladores que se resumían -según palabras de Lotito- en el hecho de que La Forestal constituía en los hechos una "república independiente".

Una de las evidencias al respecto se encontraba en el control privado del servicio público de pasajeros. Varias fueron las denuncias que recayeron por las restricciones que ejercía la compañía sobre el servicio de trenes. Una de éstas, la más autorizada, provino de "un viejo empleado de la empresa", quien luego de más de doce años terminó desempeñándose como jefe de tráfico de La Forestal. El señor Herminio Goycochea presentaba la siguiente queja ante la inspección nacional de ferrocarriles:

Que vengo a denunciar un hecho que a mi juicio implica una falta grave (...) que esa dirección general como contralor de los ferrocarriles nacionales está en el deber de prohibir (...) Resulta que en esta zona La Forestal posee varios ramales férreos, en las estaciones Margarita, Ogilvie y Villa Ana del Ferrocarril Santa Fe; ramales férreos que arrancan de la vía del ferrocarril provincial con cuyas vías empalman e internan en sus obrajes (...) Así también entiendo que sus máquinas, coches y vagones de carga no pueden entrar en las vías de las estaciones del Ferrocarril Santa Fe para hacer maniobras, etc. ${ }^{20}$

Cinco años más tarde, Lotito confirmaba dicho problema, al constatar que un obrero no podía llegar desde La Gallareta a Margarita si no era por el tren de la compañía, siendo que para obtener el pase, debía explicar para qué lo solicitaba: "Si dice que es para hacer compras, no se lo dan", comentaba el viajante, quien luego agregaba que lo mismo sucedía si se negaba a dar explicaciones ${ }^{21}$. Esta situación, que empeoraba en los pueblos donde no existían las escuelas, pues los chicos no podían llegar a los colegios distantes, le valía a Lotito un comentario irónico: "Dentro de esta república independiente, hay que pedir pasaporte cuando se quiere ir a la República Argentina, y de ésta no se puede volver con mercaderías porque en el tren no la admite. Las aduanas interiores, suprimida por la constitución, existe aquí, ¡y cómo!"’22.

Al problema del transporte, le seguía el de la educación. A pesar de que los cargos educativos eran asignados por la provincia, la compañía mantenía -al parecer- un gran nivel de discreción sobre lo que se enseñaba. Entre otras cosas, se debía ello a que los mismos centros educativos eran construidos por la misma empresa en sus propios terrenos.

\footnotetext{
${ }^{20}$ Diario Santa Fe, 12/6/1915.

${ }^{21}$ Periódico La organización obrera, 10/4/1920.

${ }^{22}$ Ibíd.
} 
Dicha capacidad de discreción era advertida por el maestro Bernardo Von Oertel, hacia 1923, al pasar revista de varios "problemas escolares”. A través de un diario local, además de quejarse por la baja cantidad de alumnos que terminaba el ciclo primario, comentaba:

Las escuelas nacionales se encuentran tácitamente bajo el patronato de la gran compañía, sin cuyo requisito, la obra está expuesta a resentirse, cuando no a esterilizarse. El hecho de que La Forestal dote a los colegios de edificio gratuito, que subvencione a los directores o las escuelas, que las poblaciones se encuentren aisladas a merced de ella y que el alumnado sea hijo del personal de la misma; todo contribuye poderosamente a que el funcionamiento de estos establecimiento deba rimar en un todo con la alternativas de la política, no del directorio, sino de la gerencia local, lo que, fácil es sugerir, puede provocar descarrilamientos si la cabeza del administrador no es serena y gusta de las triquiñuelas vecinales. ${ }^{23}$

No eran las únicas falencias. Los poblados también carecían de casillas de correo. Por ejemplo, para Santa Felicia, Lotito advertía que la función de la estafeta postal estaba a cargo de la empresa, lo que generaba muchos recelos hacia la administración, pues la correspondencia se "extraviaba" con frecuencia. Hacia 1915, el mismo Gervazoni, previamente citado, denunciaba:

No existe señor, respeto alguno por la ley nacional postal y telegráfica. Esta compañía, sin intervención ni control particular o nacional, recibe en sus escritorios la correspondencia de y para sus obreros y en la misma forma la entrega y extrae de la oficina nacional del pueblo de Margarita. La seriedad y secreto que imprime a todos sus actos el correo nacional no tiene efectos legales. Igualmente se viola con todo descaro el secreto telegráfico... ${ }^{24}$

Lo mismo denunciaba por carta J. Manuel Corvalán, quien se desempeñó durante nueve años como dependiente de almacén, balancero, cajero y capataz general de la compañía en La Gallareta: "Los telegramas y cartas -testimoniaba- estamos obligados a recibirlos y mandarlos sin ninguna seguridad ni secreto, y merecen la censura antes de aceptarlo..."25. Por cierto, la carta de denuncia que escribiera este último había sido entregada en mano al corresponsal del diario Santa Fe. Estas privaciones hacían -al decir de Lotito- que el pueblo se viera ajeno a "la fisonomía completa de una entidad civil"26.

Tanto igual ocurría con los registros de nacimientos, defunciones y matrimonios. El mismo ciudadano que se quejaba por el correo y el telégrafo, escribía:

23 Diario Tribuna, marzo de 1925 (en Ramirez y Quarin, 2005).

24 Diario Santa Fe, 10/6/1915.

25 Diario Santa Fe, 11/6/1915.

${ }^{26}$ Periódico La organización obrera, 3/4/1920. 
Jasinski. El régimen social de la forestal en sus primeras décadas.

El control sobre nacimientos, defunciones o matrimonios créelo innecesario esta compañía. Los pobres siervos obreros que fallecen en este feudo denominado La Gallareta no tienen lugar sagrado o camposanto donde reciban sus despojos humana o cristiana sepultura (...) Otros cadáveres de obreros que tienen quien pueda pagar el transporte en los trenes de esta compañía van embolsados hasta el cementerio del vecino pueblo de Margarita. Así tratan estos déspotas extranjeros los cuerpos de los infelices obreros que trabajaron en su fábrica ${ }^{27}$.

Existían, además, en algunos poblados, los clubes sociales (diferenciados para empleados y obreros) y las actividades recreativas (como el scautismo y el fútbol), pero no se permitía -hasta finales de la década de 1910- ni el sindicato ni el local político. Recién hacia 1911, los trabajadores de Villa Guillermina lograron constituir la primera sociedad de socorros mutuos, que sólo hacia 1919 se transformó en un sindicato, al cual la empresa combatió con empeño (Jasinski, 2012).

\section{"Seguridad" y "Justicia”}

Tan grave como lo que venimos mencionando era el hecho de que los servicios de la seguridad y la justicia pública se confundieran con los de la fuerza y el capricho privados:

La justicia de paz no existe -decía Gervazoni en 1915- en estos dominios. Aquí no se consultan leyes. Miles de casos lo comprueban y el machete policial lo testifica. Hace poco, con el hacha en la mano, fue derribada la puerta de la humilde vivienda del vecino don Pedro Aldasoro. Sus mueblecitos y sus ropas de vestir fueron lanzados a la calle pública: este siervo habíase resistido a abandonar los dominios de La Forestal ${ }^{28}$.

Seis años más tarde, en 1921, otra denuncia puntualizaba sobre las comisiones recibidas por la policía:

¿Quién ignora que el juez de paz de Guillermina tiene doscientos pesos mensuales de subvención, trescientos el comisario del mismo lugar, doscientos el de Villa Ana y doscientos el de Tartagal? [...] Y bien, el que entonces era juez de paz en Guillermina, hoy es comisario en el mismo punto y el que era comisario allí hoy está en Villa Ana, no obstante estar ambos con el proceso abierto en el Superior Tribunal. ${ }^{29}$

\footnotetext{
27 Diario Santa Fe, 10/6/1915.

2 Diario Santa Fe, 10/6/1915.

29 Diario Santa Fe, 30/6/1921.
} 
En el mismo sentido, el diputado Belisario Salvadores denunciaba que en Villa Guillermina el presupuesto en vigencia asignaba a un comisario general 150 pesos mensuales, siendo la empresa, "por regla general", árbitro de los nombramientos, al fijarles una partida de 450 pesos extra ${ }^{30}$. Mientras que el ya citado Goycochea indicaba que durante su actuación como jefe de tráfico, la compañía le había ordenado entregar en mano propia al jefe de estación de Margarita, a los cambistas, al jefe de correos, al juez de paz, a los comisarios de policía y, en una palabra, "a todas las autoridades públicas", las gruesas sumas que como sobresueldos o subvenciones les tenía asignadas ${ }^{31}$.

Pero no sólo la empresa colaboraba con los sobresueldos de estos funcionarios. Los permisos de explotación del juego, del baile, de la bebida y de la prostitución también contribuían a su buen pasar. Una nota editorial del diario Santa Fe así lo indicaba:

En la casa de baile, en la cancha de taba, negocios en que estaban interesados el comisario y la administración. He así como la comisaría de Guillermina les producía a los comisarios de 1.500 a 2.000 pesos mensuales, y en escala inferior aunque usando los mismos medios todos los comisarios del norte. Nadie lo ignora en Santa $\mathrm{Fe}^{32}$.

Pero aún más interesante resultaba la confesión de un miembro de la misma fuerza policial. El ex comisario de Villa Guillermina, de apellido Del Castillo, respondía a las denuncias aparecidas en el diario provincial. Al intentar exculpar a los agentes públicos, involucraba a las mismas autoridades políticas departamentales y, de paso, confirmaba las gracias que otorgaba La Forestal:

No creo que cualquiera de los comisarios de estos distritos en que se bebe, se baila y se juega con exceso públicamente, sea

\footnotetext{
${ }^{30}$ Archivo General de la Provincia de Santa Fe, Legislatura Provincial, Diario de Sesiones, 1921, t. III. Valga, aunque tarde, la aclaración. Merecen las referencias a estas denuncias legislativas y periodísticas hacer un breve comentario sobre el contexto político provincial. Con la reforma electoral nacional introducida en 1912, el radicalismo santafesino regresó a la arena del voto, pero no pudo hacerlo bajo una única conducción, ni mucho menos bajo las directivas del Comité Nacional. La primera ruptura entre "disidentes" (que ganan la gobernación en 1916) y "oficialistas" (alineados con las directivas del Comité Nacional, luego "nacionalistas"), tiene la particularidad que no es aprovechada por ningún partido conservador, lo que también permite que la política provincial se dirima como interna partidaria. El Partido Demócrata Progresista, liderado por Lisandro de la Torre, apoya en algunas circunstancias a la fracción disidente, en vistas de la oposición al gobierno nacional. Hacia 1918, del radicalismo disidente surge una nueva fisura: los elizaldistas rosarinos (seguidores del vicegobernador renunciante) y más tarde se subdividen en dos grupos: nordistas y sudistas. Este "cisma" radical se produce en el contexto de un clima de reformismo político, social y cultural que, como sostienen en un reciente estudio Macor y Piazzesi, alteran las fronteras partidarias y la prensa aparece como el gran espacio de formación de una opinión pública sensibilizada y demandante (Macor y Piazzesi, 2010). En este marco, la cuestión social, con todas sus aristas, se convierte en un eje jerarquizado del debate político, anunciándola como una asignatura pendiente del partido oficial, interesando aquí las denuncias hechas contra un régimen social -el de La Forestal- que se consolida bajo el franco auspicio del radicalismo santafesino en el gobierno.

31 Diario Santa Fe, 12/6/1915.

32 Diario Santa Fe, 2/3/1921.
} 
Jasinski. El régimen social de la forestal en sus primeras décadas.

el único culpable o responsable de ese mismos estado de cosas, los creo tan culpables como a él, a sus superiores inmediatos, que si no los autorizan, los toleran, algunos con intereses de compartir las ganancias, como el ex secretario de la Jefatura de General Obligado don Irene V. Maidana, que en sus tiempo me quería exigir una mensualidad de pesos 200 -y como yo no coimeaba en ninguna forma y solo gozaba de la subvención que La Forestal da a los comisarios (como es público) no pude complacerlo dando esto lugar a que se me ordenara pasar a Reconquista. ${ }^{33}$

Este esquema de corrupción se formalizaba al prohibir la compañía que la misma comisaría llevara el escudo oficial, como constara en las denuncias trascritas de varios vecinos de la zona. Nadie ignoraba, además, que los comisarios, subcomisarios y jueces de paz, afianzaban este sistema de corrupción y prebendas con los fuertes y siempre eficientes vínculos familiares (Jasinski, 2012).

\section{La "intendencia"}

Pero si aún bajo estas condiciones el pueblo tenía comisario, maestro y juez de paz, no se puede decir que tuviera una verdadera autoridad política. Ni siquiera en un pueblo como Villa Guillermina que, hacia fines de la década de 1910, contaba con más de cinco mil habitantes, había elecciones comunales. En efecto, el "intendente" era nombrado por el gerente y en lugar de una municipalidad funcionaba la "Sección Pueblos" de la compañía. Hacía notar Salvadores en uno de sus discursos ante la legislatura provincial que el supuesto intendente y sus empleados subordinados que constituyen las autoridades comunales del pueblo "no tienen absolutamente nada que ver con nuestro régimen municipal". Eran simplemente "funcionarios que nombra, paga y manda la empresa" ${ }^{34}$.

Esta situación también quedó reflejada en los diálogos de Tierra extraña entre el protagonista y el gerente de Villa Guillermina, quien aseguraba que sobre sus hombros descansaba la tarea de ser la municipalidad del pueblo. Y más tarde, cuando el mismo protagonista, un hombre de campo, explicaba que si ya el "intendente" tenía un rol destacado, ver al gerente de la compañía le generaba una emoción, "la misma que experimentaría ahora si viera pasar al presidente de la República...” (Vagni, 1949).

Es cierto, para elegir diputados provinciales, nacionales, gobernador o presidente, los pobladores de aquella región tenían permitido el voto. Pero aún cuando se tratara de elecciones posibles, la situación no era más que una "farsa electoral", como lo describiera Roberto Vagni para la década de 1930 o como también lo denunciara el citado vecino Gervazoni para 1915:

\footnotetext{
33 Diario Santa Fe, 19/3/1921.

${ }^{34}$ Archivo General de la Provincia de Santa Fe, Legislatura Provincial, Diario de Sesiones, 1921, t. III.
} 
En el año 1912, los hijos del país que rindiendo homenaje a la patriótica proclama donde el doctor Roque Sáenz Peña invita al pueblo argentino a cumplir con sus deberes cívicos diciéndoles, 'Quieran votar', pagaron con su puesto y expulsión de estos dominios el delito de haber emitido el voto libre sin consentimiento de sus amos y señores que forman la compañía La Forestal ${ }^{35}$.

El también citado ex jefe de tráfico Goycochea denunciaba el mismo hecho, al hacer constar que la empresa había ejercido presión y obligado a todos los empleados argentinos a emitir su voto cívico por los candidatos del partido de la Coalición durante las elecciones provinciales de 1912: "Los ciudadanos que se negaron a ello pagaron con su puesto la altivez de carácter”, comentaba ${ }^{36}$.

\section{Impugnaciones al régimen social de La Forestal}

Lo dicho hasta aquí representa los aspectos más crudos del dominio ejercido en lo que hemos denominado régimen social de La Forestal. Por supuesto, no podría afirmarse sin más que las referidas condiciones hubieran generado por sí solas un movimiento popular de impugnación a lo establecido. Un conjunto de circunstancias, entre las que se encuentran además las mismas condiciones económicas y técnicas-productivas, imaginarios, demandas y expectativas de los mismos pobladores y trabajadores de los poblados forestales, y los contextos políticos y sociales, como la llegada a las fábricas de tanino de hombres con experiencia sindical, contribuyeron a dar forma al evidente descontento que había generado el absorbente dominio establecido por la compañía inglesa. Esta situación, que comenzó hacia 1918 y que he comentado en otro lugar (Jasinski, 2012), necesita ser sintetizada ahora.

Es que si bien existieron, hacia comienzos de la década de 1910, algunos intentos de organización popular, de carácter autónomo, en los poblados forestales, recién hacia fines de 1918 tendría lugar la primera huelga taninera. En Villa Guillermina y en Villa Ana, se fundaron sociedades de socorros mutuos, pero algunos datos nos indican que fueron rápidamente neutralizadas ${ }^{37}$. En paralelo, algunas solicitudes y reclamos individuales ante la gerencia terminaron con la más básica medida empresarial: el despido y expulsión de los demandantes. Recién hacia 1918, tuvo lugar en Villa Guillermina un paro de actividades y la presentación de un extenso pliego de exigencias laborales. En febrero, marzo y mayo de 1919, nuevas protestas tuvieron como protagonistas a los obreros de las fábricas de tanino. Las acciones eran motivadas cada vez más por una mayor cantidad de demandas,

35 Diario Santa Fe, 10/6/1915.

36 Diario Santa Fe, 12/6/1915.

${ }^{37}$ En Villa Guillermina, quien más tarde sería el secretario general del sindicato taninero, el electricista Teófilo Lafuente, figuraba como fundador de la sociedad mutualista hacia 1911, pero cinco años más tarde se reorganizó la sociedad y quedó relegado. En el caso de Villa Ana, la fundación de la sociedad obrera tuvo lugar en la casa de quien figuró luego en varios registros como el mayordomo y organizador de la fuerza de choque de La Forestal (Jasinski, 2012). 
que excedían por completo a las de carácter económico. Pero lo sustancial fue que a partir de marzo, las medidas de sanción obreras presentaron una nítida coordinación con los dirigentes sindicales de la organización nacional que entonces estaba articulando la mayor parte del movimiento obrero a nivel nacional: la FORA IX, de carácter sindicalista.

Hacia mediados de 1919, quienes organizaban el movimiento ahora sindical en La Forestal, recorrían todos los poblados forestales, acompañados por los delegados novenarios, para convocar a los trabajadores del monte y pueblos tanineros. No sucedió esto sin que se disparara la reacción patronal. Las giras de propaganda sindical, las deliberaciones obreras, la organización que se difundía a una velocidad sorprendente, tuvo como respuesta la llegada de las fuerzas de represión provincial y la organización de las fuerzas de choque privadas. Los enfrentamientos y las primeras víctimas fatales no tardaron en llegar. Hacia diciembre de 1919, se produjo entonces la primera huelga general en territorio de La Forestal. La acción fue planificada y coordinada con gran anticipación. El Directorio se había negado a aceptar un pliego que contenía 35 demandas de todo tipo. La última exigía simplemente "mayor respeto" hacia los obreros. La huelga duró casi un mes y se contabilizaron sustanciosas pérdidas materiales para la empresa. La demostración de fuerza obrera fue tal que, por ejemplo, unos trescientos trabajadores marcharon armados por las calles de Tartagal. El pliego fue finalmente aceptado por la compañía, con algunas escasas modificaciones. El gran ganador había sido el Sindicato de Obreros en Tanino y Anexos de La Forestal.

La compañía, sin embargo, no dejó de ejercer una fuerte resistencia. Concedió cuanto creyó necesario, pero dilató la aplicación de los convenios de tal forma que puso en jaque los iniciales éxitos de los trabajadores y provocó el cuestionamiento de la estrategia obrera seguida hasta entonces. Una sofisticada contra-estrategia empresarial le permitió al Directorio retomar pronto las riendas del conflicto, que se ya se presentaba como ciclo de protesta. La ingeniería empresarial tuvo como eje el cierre de fábricas y la constitución de una fuerza represiva que logró formar con el fuerte compromiso del gobierno provincial, entonces a cargo del radical nacionalista Enrique Mosca. Así nació la Gendarmería Volante, que pronto fue objeto de numerosas denuncias por torturas y abusos de todo tipo. El final de la historia no pudo ser peor. El cierre de fábricas y la desorganización de los trabajadores, producto de un selectivo proceso de expulsión y persecución empresarial, detonó una rebelión popular ${ }^{38}$, cuya sofocación causó una incontable cantidad de muertes. Sólo los redactores de La Vanguardia se animaron a estimar entre 500 y 600 los trabajadores y pobladores masacrados ${ }^{39}$.

\section{Conclusión}

El desmonte de los quebrachales no comenzó con La Forestal. Pero a poco de llegar al chaco santafesino, en 1906, esta compañía inglesa clausuró el espacio regional,

\footnotetext{
${ }^{38}$ Tomamos el concepto de "rebelión" presentado por Nicolás Iñigo Carrera, como un genérico de la acción de las clases populares, que dibuja una escala de formas desde la más espontáneas hasta las más sistemáticas y conscientes (Iñigo Carrera, 2008).

${ }^{39}$ La Vanguardia, 9/2/1921.
} 
profundizó algunas características existentes y creó nuevas, configurando un asfixiante régimen social, que no tardó en ser cuestionado, primero con medidas aisladas de vecinos y acciones pre-sindicales de sus trabajadores y, finalmente, hacia finales de la década de 1910, por poderosos sindicatos. Esta historia apenas la hemos esbozado aquí y está contada en otro lugar (Jasinski, 2012).

En este artículo, buscamos poner de relieve algunas de las características más representativas de la vida en los poblados forestales, presentes tanto en los campamentos más pequeños como en los pueblos más importantes. Claro que existieron en la región, más específicamente en sus contornos, pueblos que tuvieron un desarrollo independiente de La Forestal. Las ciudades de Vera, Reconquista y Villa Ocampo, eran puentes de acceso al bosque santafesino. Las Toscas, Lanteri, Flor de Oro, entre otros, eran poblados menores, vinculados a otras actividades productivas. El resto de la región, en cambio, sí estuvo bajo dominio de la compañía británica.

A partir de numerosos y variados testimonios pocos o nada explorados, ya fueran informes oficiales, carta de lectores, crónicas periodísticas, novelas y, principalmente, un folleto escrito por un delegado sindical en gira, podemos representarnos muchas de las circunstancias que fueron animando la conformación de un inédito movimiento de protesta y un singular proceso de sindicalización, que posicionó a un variado conglomerado social en antagonismo con la omnipresente compañía.

Decíamos que resultaba arriesgado suponer que las características del régimen social descrito pudieran explicar por sí mismas la acción popular de fines de década, pero sin dudas alimentaron en gran medida el descontento social de los pobladores del norte santafesino: no sólo de aquellos que directamente vendían su fuerza de trabajo en las fábricas de tanino o en los montes de quebracho, también de todos aquellos que involuntariamente se encontraban bajo el dominio de La Forestal.

El hecho de que tanto la construcción de las viviendas, la prestación de servicios esenciales y secundarios, desde el agua, el transporte, hasta la atención sanitaria, estuvieran bajo la exclusiva prerrogativa empresaria, da cuenta del cerrado control que se ejercía sobre cada uno de los sujetos que allí habitaban. Por otra parte, la advertencia hecha por el maestro Von Oertel, acerca de la rectoría de la gerencia local sobre el funcionamiento del establecimiento educativo, las quejas por el control ejercido sobre el servicio postal y telegráfico y por la forma en que debían trascender las denuncias a la prensa provincial, enseñando un cierre de las comunicaciones hacia afuera del espacio regional, nos hace suponer una notable preocupación de la patronal por el control en la circulación de discursos e imaginarios que configuraban aquellas subjetividades. La airada reacción de las gerencias ante las giras de propaganda sindical que tuvieron lugar con posterioridad, da cuenta de la amenaza que suponían para las representaciones establecidas.

Por supuesto, no fue sólo el dominio sin más el que acusó impugnaciones cada vez mayores. Las numerosas denuncias y relatos que presentamos dan cuenta también de un franco descontento hacia las características específicas de este dominio: la precariedad de las viviendas, el notorio desprecio por la salubridad y alimentación de la población, la 
Jasinski. El régimen social de la forestal en sus primeras décadas.

inexistencia de genuinos servicios públicos y, fundamentalmente, la estafa contenida en el esquema de retribuciones salariales y circulación monetaria, ponían serios obstáculos a la posible construcción de un consentimiento hacia el dominio ejercido.

A todo esto se agregaban dos cuestiones fundamentales. La primera, el aspecto represivo. Se trata de la dirección que la compañía ejercía sobre los hilos de la justicia y la seguridad, para el caso, mal llamadas públicas; al menos, tal como lo enseñan las numerosas denuncias de un sistema de corrupción, licencias y subvenciones, montado en la región. Así, a la mínima presencia de una construcción estatal en el territorio de La Forestal, se agregaba su carácter cómplice de la dominación empresaria, toda vez que lo que se expresaba a través de los agentes públicos era la voluntad de la compañía.

La segunda cuestión es la de la representación. En efecto, en momentos en que, a nivel nacional, se ponía en vigencia la nueva ley electoral, denominada "Ley Sáenz Peña, que instituía el voto secreto y obligatorio para los hombres, y se ampliaba, de esta forma, el sistema de representación en todas las provincias y a nivel nacional; en los territorios de La Forestal, la situación distaba en mucho de asemejarse. Si bien es cierto que a los habitantes de estos poblados del norte santafesino se les presentó la oportunidad de votar en las diferentes elecciones nacionales y provinciales -no olvidando las denuncias de "farsa electoral"-; a nivel local, el sistema de representación política que expresara la voluntad popular -tal como lo hicimos notar- era inexistente. Frente a esta carencia, tampoco se hacía factible la posibilidad de acceder a otras instancias representativas. Los sindicatos estaban prohibidos de hecho y las asociaciones mutualistas que surgieron desde comienzos de la década de 1910 carecieron de autonomía, toda vez que, aún cuando el gobierno provincial les concedió la personería legal hacia mediados de la década, sufrieron el patronazgo de las gerencias. Así, se hacía notoria la ausencia de un genuino y efectivo canal de representación y participación local para los "nuevos ciudadanos". Queda pendiente un análisis más exhaustivo de la posible existencia de una relación directa entre esta carencia y la determinación, principalmente de los trabajadores, de abocarse a la conformación de potentes representaciones sindicales, en función de dar lugar a organizaciones relativamente autónomas de las voluntades estatal y empresaria.

Considerando este escenario, no era difícil imaginar que se acumularan tensiones y todo explotara de un día para otro. Entrada la década de 1910, comenzó el proceso de organización popular, una historia de luchas, avances y retrocesos, una historia dinámica, de enfrentamientos en todos los planos con las gerencias de cada pueblo y con el Directorio de la compañía. Así, en vistas a las agobiantes características del régimen social configurado, el conflicto social existente se presentó, prácticamente, sin mediaciones. No existían y, aún más, estaban vedados los canales capaces de ejercer presiones disolventes de los descontentos que emergían. Por ello, la empresa se vio obligada a responder por los salarios, por las ocho horas, por las condiciones de trabajo, pero también por la provisión de alimentos, por la instrucción y la salud de los trabajadores, por el transporte y la vivienda. En esta "república independiente", los trabajadores encontraron a los destinatarios de todas sus demandas corporizados en un mismo sujeto: La Forestal. 


\section{Mapa Carretero de Santa Fe. Antiguo territorio de La Forestal}

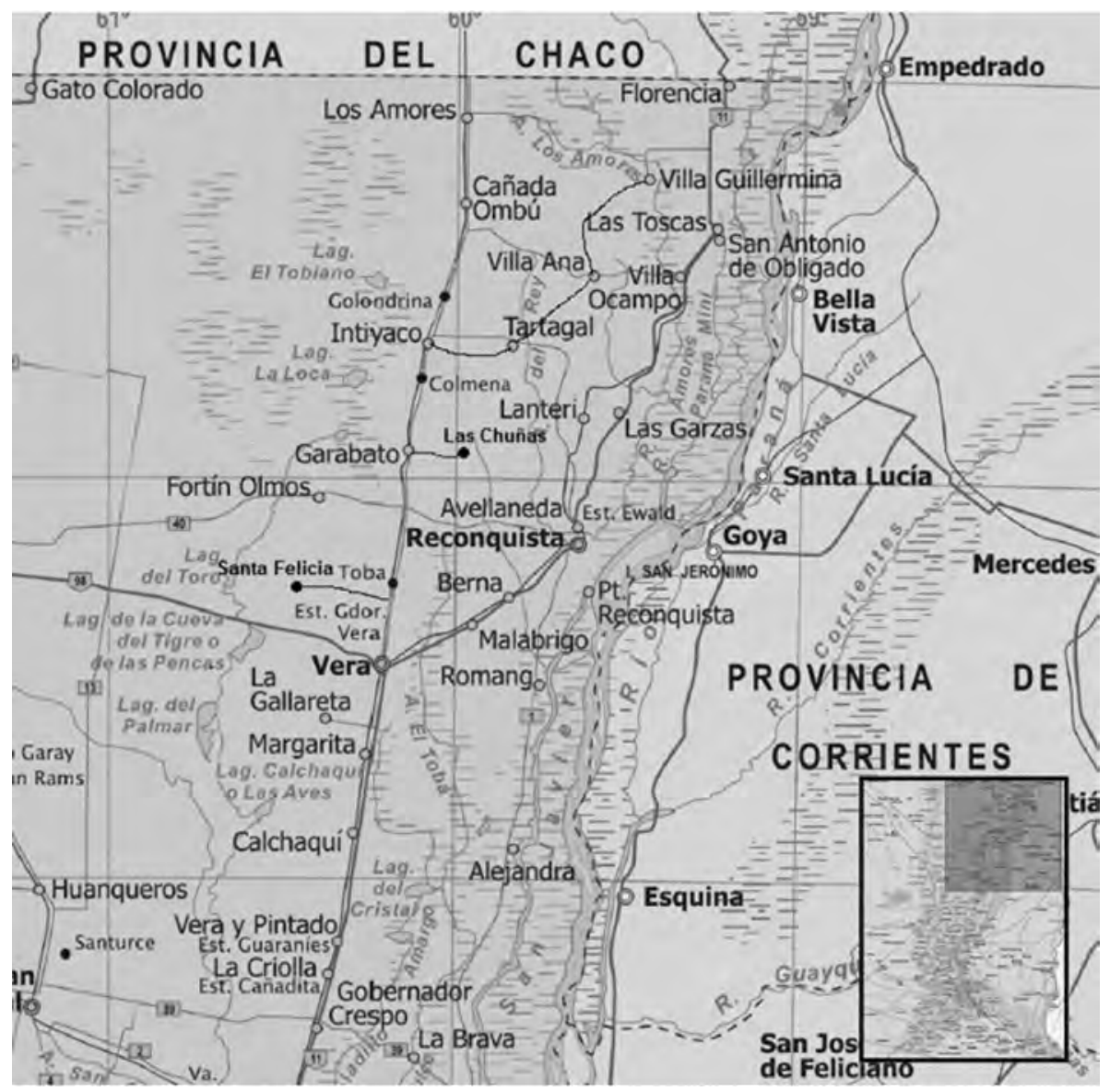

Fuente: Instituto Geográfico Nacional http://www.ign.gob.ar/descargas/mapas/zip/santa\%20fe\%20A4.zip

\section{Referencias bibliográficas}

Abad de Santillán, Diego. 1971. Gran Enciclopedia Argentina. Buenos Aires, TEA.

2005. La Fora, ideología y trayectoria, Buenos Aires, Libros de Anarres.

Adamovsky Ezequiel. 2007. "Historia y lucha de clases. Repensando el antagonismo social en la interpretación del pasado (y de vuelta sobre un debate ausente en la historiografía argentina)". En: Revista El Nuevo Topo, Buenos Aires, $n^{\circ} 4$.

Belloni, Alberto. 1960. Del anarquismo al peronismo, historia del movimiento obrero argentino, Buenos Aires, Ediciones Documentos.

Bernabé Vargas, José. 2003. "Sudor y sangre de quebracho" (texto inédito). En: Edición 4, Reconquista.

Bialét-Massé, Juan. 1985. Informe sobre el Estado de las clases obreras a comienzos del siglo, Buenos Aires, Centro Editor de América Latina.

Bittloch, Eduardo, Sormani, Horacio. 1997. "Los enclaves forestales de la región chaqueño- 
Jasinski. El régimen social de la forestal en sus primeras décadas.

misionera”. En: Revista de Divulgación Científica y Tecnológica, Asociación Ciencia Hoy, Vol.7, No 37.

Bonaudo, Marta y Bandieri, Susana. 2000. "La cuestión social agraria en los espacios regionales". En: Democracia, conflicto social y renovación de ideas (1916-1930), Nueva Historia Argentina, t. VI, Buenos Aires, Sudamericana.

Brianza, Elizabeth. 2007. Fichas y vales del norte de Santa Fe. Finales de Siglo XIX y principios de siglo XX. Santa Fe, Anexo Sur de Chaco.

Bünstorf Jürgen. 1982. "El papel de la industria taninera y de la economía agropecuaria en la ocupación del espacio chaqueño". En: Folia Histórica del Nordeste, N9. Resistencia, Instituto de Investigaciones Geohistóricas-Conicet, Instituto de historia-UNNE.

Castoriadis, Cornelius. 1988. "El régimen social de Rusia". En: Ídem., Los dominios del hombre: las encrucijadas del laberinto, Barcelona, Gedisa, pp 29-49.

Girbal Blacha, Noemí. 1993. "Explotación forestal, riesgo empresario y diversificación económica e inversiones en el Gran Chaco, 1905-1930”. En: Revista de Historia de América $\mathrm{N}^{\circ}$ 116, Julio-Diciembre. México, Instituto Panamericano de Geografía e Historia.

Godio, Julio. 1989. Historia del Movimiento Obrero Argentino, 1870-2000, t. I, Buenos Aires, Legasa.

Gori, Gastón. 1991. La Forestal. La tragedia del quebracho colorado. Santa Fe, Edición Distribuidora Litar.

Iñigo Carrera, Nicolás. 1988. La violencia como potencia económica. Chaco 1870-1940, Buenos Aires, Centro Editor de América Latina. 2008. “Algunos instrumentos para el análisis de las luchas populares en la llamada Historia Reciente”, En Iñigo Carrera N., López Maya M., Calveiro P.: Luchas contrahegemónicas y cambios políticos recientes de América Latina, 1a ed., Buenos Aires, Consejo Latinoamericano de Ciencias Sociales - CLACSO.

Iscaro, Rubén. 1973. Historia del movimiento sindical. t. III, Buenos Aires, Fundamentos.

Jasinski, Alejandro. 2012. Revuelta obrera y masacre en La Forestal. Buenos Aires. Editorial Biblos [En edición].

Macor Darío y Piazzesi Susana, "El Radicalismo y la política santafesina en la Argentina de la primera república”. En: Revista Estudios Digital, Centro de Estudios Avanzados de la Universidad Nacional de Córdoba, № 23-24, 2010.

Marotta, Sebastián. 1970. El movimiento sindical argentino. Su génesis y desarrollo, t. I y II, Buenos Aires, Editorial Calomino.

McAdam, Doug; Tarrow, Sidney; Tilly, Charles. 1996. "To map contentious politics". En: Mobilization, v. 1, $\mathrm{N}^{\circ}$ 1, Septiembre. Indiana, Centro de Estudios de Movimientos Sociales y Cambios Sociales, Departamento de Sociología, Universidad de Notre Dame.

Ospital, María Silvia. 1990. "Condiciones laborales en la explotación forestal gran chaco argentino (1890-1920)”. En: Folia Histórica del Nordeste, № 9, Resistencia, Instituto de Investigaciones Geohistóricas-Conicet, Instituto de historia-UNNE.

Palacios, Alfredo. 1960. El nuevo derecho, Buenos Aires, Claridad.

Panettieri Jorge. 1959. Los trabajadores. Buenos Aires, Jorge Álvarez.

Ramírez, César y Quarin, David. 2005. La Gallareta, una mirada histórica en el año de su centenario. Santa Fe. Comuna de La Gallareta.

Vagni, Roberto. 1949. Tierra extraña. Buenos Aires, Editorial J.a.c.k. 